TREE-RING RESEARCH, Vol. 63(1), 2007, pp. 15-26

\title{
DENDROCLIMATOLOGICAL INVESTIGATIONS OF SEA BUCKTHORN (HIPPOPHAE RHAMNOIDES) AND RECONSTRUCTION OF THE EQUILIBRIUM LINE ALTITUDE OF THE JULY FIRST GLACIER IN THE WESTERN QILIAN MOUNTAINS, NORTHWESTERN CHINA
}

\author{
SHENGCHUN XIAO* \\ Cold and Arid Regions Environmental and Engineering Research Institute \\ Chinese Academy of Sciences \\ Lanzhou 730000, China \\ HONGLANG XIAO \\ Cold and Arid Regions Environmental and Engineering Research Institute \\ Chinese Academy of Sciences \\ Lanzhou 730000, China \\ OSAMU KOBAYASHI \\ The University Forest \\ Faculty of Agriculture \\ Ehime University \\ Ehime 7908566, Japan \\ and
}

PUXING LIU

College of Geography and Environment Sciences

Northwest Normal University

Lanzhou 730070, China

\begin{abstract}
Radial growth characteristics of a high-elevation shrub species, sea buckthorn (Hippophae rhamnoides), were investigated at four sites in a river valley at altitudes ranging from 3,333 to $3,820 \mathrm{~m}$ a.s.l. close to the terminus of the July First Glacier in the western Qilian Mountains of northwestern China. Radial growth of the sea buckthorn was significantly and positively correlated with the mean monthly temperature in June of the current growing season. Based on the fact that fluctuations in the shrub's radial growth and the glacier's equilibrium-line altitude (ELA) are affected by climatic variables, a tree-ring width chronology of the four sites was used to reconstruct the ELA from 1950 to 2003. The resulting ELA model explained more than 55.3\% of the variance in the ELA of the July First Glacier series. On a decadal time scale, the cumulative-departure curve of the reconstructed ELA series showed an increasing trend from the 1950s to the mid-1960s, followed by a descending trend from the mid-1960s to the mid-1970s. The ELA appears to have remained stable from the mid-1970s to the mid-1990s, but has displayed dramatic variations during the past decade.
\end{abstract}

Keywords: tree-ring analysis, dendrochronology, dendroglaciology, July First Glacier, equilibrium line altitude (ELA), Hippophae rhamnoides, shrub growth.

\section{INTRODUCTION}

The response of vegetation to regional climate change has received increasing attention in climate change studies. A variety of approaches have been used to study past climate change, such as ice and

*Corresponding author: xiaosc@ns.lzb.ac.cn lake sediment cores and tree-ring records. Studies have investigated several shrub species (GrissinoMayer 1993), Tamarix spp. (Chen 1996; Yang et al. 1996; Xiao et al. 2005), Reaumuria soongorica (Xiao et al. 2006), and sea buckthorn (Hippophae rhamnoides) (Schweingruber 1996), and most have used dendrochronology to study climate 
change (Lipp et al. 1996), lake level changes (Begin and Filion 1995; Xiao et al. 2005), and river flow changes and forest dynamics (Friedman et al. 1996; Schweingruber 1996; Stromberg 1998). Shrubs have shorter lifespans than trees, and thus offer a shorter time span for the interpretation of climatic conditions. However, their location close to habitat extremes where no trees are found makes them useful and sensitive tools for understanding recent environmental trends and the combination of factors involved in stand dynamics and local conditions (Begin and Filion 1995). In addition, the sampling of discs allows accurate crossdating using two or more radii on the same plane. However, sampling of these shrub discs will completely destroy the shrub, so this approach should be judiciously applied, especially in ecologically fragile areas.

Glacier fluctuations have frequently been used as indicators of past climate variations over a range of time scales (Benn and Lehmkuhl 2000). However, most glacier records cover only short periods (typically, the late 20th Century). Palaeoclimatic reconstructions based on the limits of former glaciers commonly use estimates of the associated equilibrium-line altitude (ELA). This line marks the position where, over a period of 1 year, the accumulation of snow is exactly balanced by ablation of the glacier (Paterson 1994; Shi 2000). Glacier ELA is thus sensitive to variations in precipitation and air temperature; it increases with decreasing snowfall or increasing frequency of above-freezing air temperatures, and vice versa (Benn and Lehmkuhl 2000). Fluctuations in ELA therefore provide an important indicator of glacier response to climate change, and allow reconstructions of former climates and the prediction of future glacier behavior. As a consequence, former ELAs provide a potentially powerful method of quantifying palaeoclimates in regions where other forms of evidence are lacking (Benn and Lehmkuhl 2000).

However, direct measurements of glacier mass balance and ELA are labor-intensive, expensive to obtain, and relatively rare as a result of these problems. As an alternative, tree growth patterns have been used to reconstruct glacier behavior and mass balance, with encouraging results (Watson and
Luckman 2004; Larocque and Smith 2005). Because precipitation and temperature directly influence tree growth, glacier mass balance, and ELA, synchronous responses in these parameters are expected. Thus, tree-ring records can be used to construct robust proxy records of glacier mass balance and ELA (Larocque and Smith 2005). Where trees are not available for sampling, shrubs may provide a viable alternative.

The purpose of the present study was to examine the response patterns of shrub radial growth to climate change at the July First Glacier in the western Qilian Mountains of northwestern China, and to reconstruct past ELA fluctuations using shrub-ring chronologies. If the approach provides reliable data, the shrub-ring record will improve our understanding of regional climate variability on an inter-annual scale in the western Qilian Mountains. The proxy record may also provide information useful for water resource planning by local governments.

\section{DATA AND METHODS}

\section{Study Area}

The Qilian Mountains are located at the northeastern edge of the Qinghai-Tibetan Plateau in northwestern China (Figure 1). The western part of the Qilian Mountains, with elevations $>4,000$ $\mathrm{m}$ a.s.l., is the water source for many of China's interior river systems, including the Beidahe River, Shulehe River, Danghe River, and Hartenhe River (Liu et al. 2002). The mountains include a total of 650 glaciers. The area covered by this icefield is about $290 \mathrm{~km}^{2}$, and the ice volume is about 10.37 $\mathrm{km}^{3}$. Meltwater from the glaciers accounts for about $15.5 \%$ (range: 1.8 to $35.6 \%$ ) of the flow of the above mentioned rivers during warmer seasons (Wang et al. 1984).

\section{Climate, Glacier Mass Balance, and ELA in the Western Qilian Mountains}

Mean annual air temperature in the western Qilian Mountains is $-2.9^{\circ} \mathrm{C}$, and the annual total precipitation averages $283 \mathrm{~mm} /$ year (normals from 1957 to 1995 recorded at the Tuole meteorological station, $38^{\circ} 49^{\prime} \mathrm{N}, 98^{\circ} 25^{\prime} \mathrm{E}, 3,360 \mathrm{~m}$ a.s.l.). Precip- 


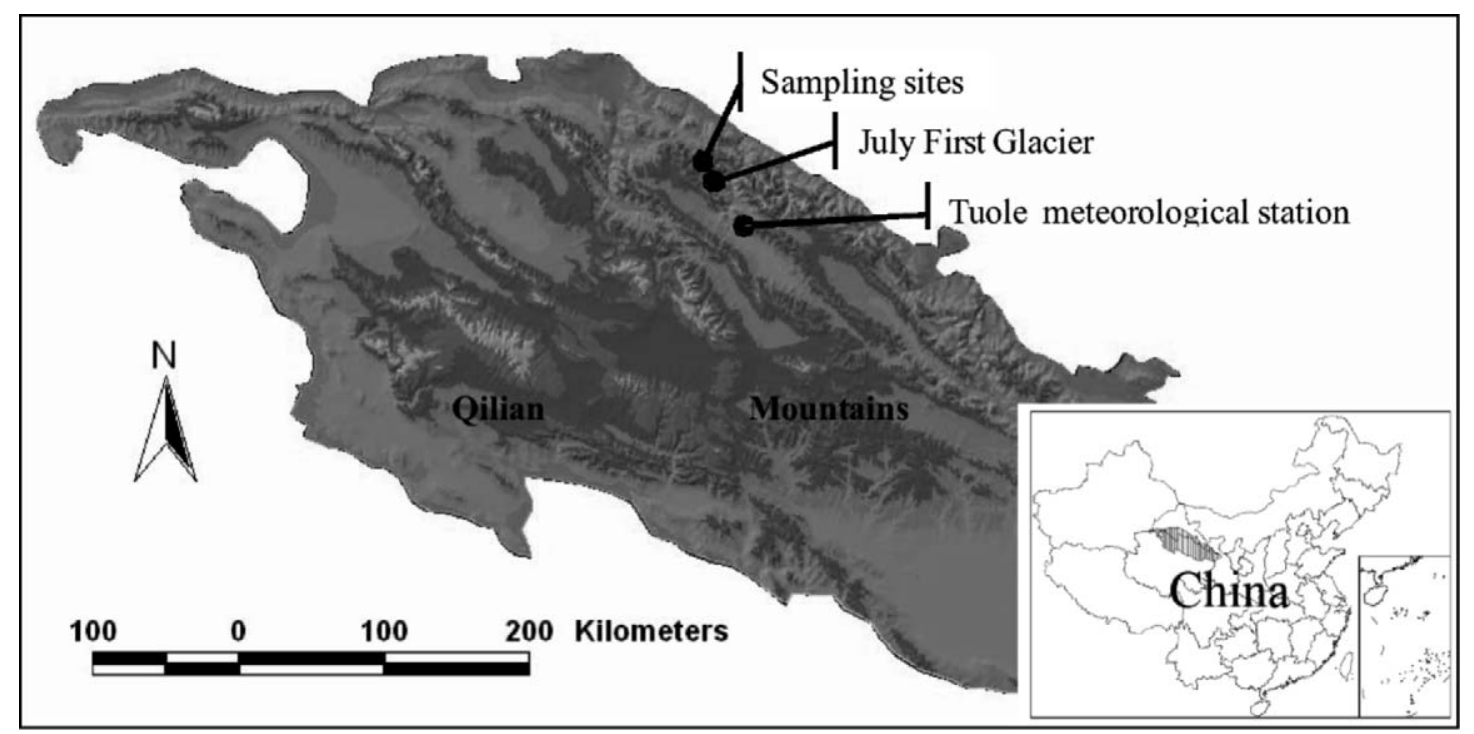

Figure 1. Location of the study site in the western Qilian Mountains of northwestern China.

itation in the Qilian Mountains is monsoonal, and thus occurs mainly in the warmer season (from May to September), which accounts for $82 \%$ of the total annual precipitation (Figure 2). Rainfall occurs from June to August, and this period accounts for about $30 \%$ of the total precipitation from May to September (Gao and Yang 1984). As shown in Figure 2, the air temperature is $>0^{\circ} \mathrm{C}$ from May to September in the Qilian Mountains, and late May to August is the primary growing season, with temperatures $>5^{\circ} \mathrm{C}$. The glaciers in

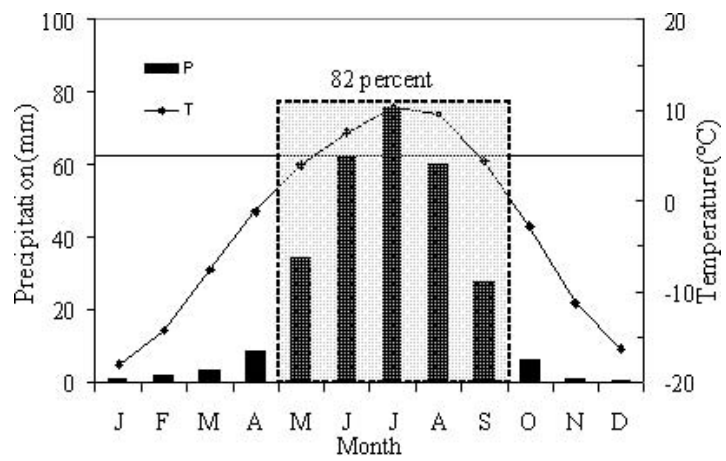

Figure 2. Climate characteristics in the western Qilian Mountains. The total percentage of precipitation (82\%) that occurs from May to September, which also represents the growing season (mean monthly temperature $\geq 5^{\circ} \mathrm{C}$, shown by the horizontal line in the graph), is also shown. the Qilian Mountains display a strict continental character. Therefore, changes in glacier mass balance occur mainly during the warm season because precipitation is affected by the monsoon that occurs mainly during the warm season (Kang and Ding 1981; Wang et al. 1984; Pu et al. 2005).

Changes in the glacier's mass balance and ELA result from the combined effects of rainfall and temperature during the warm season. In the study area, there are four main climatic types that result from different annual combinations of cold and warm temperatures with wet and dry weather (Figure 3). For example, in the wet-cold year 1983, total rainfall from June to August was $292 \mathrm{~mm}$, but the mean monthly temperature was only $7.8^{\circ} \mathrm{C}$. In contrast, total rainfall in the warm-dry year 1961 was only $127 \mathrm{~mm}$, but the mean monthly temperature was $10.0^{\circ} \mathrm{C}$. A positive net mass balance for glaciers generally occurs in wet years, whereas a negative net balance occurs in warm years (Kang and Ding 1981).

Previous studies of historical documents, tree rings, ice cores, and glacial moraines have shown that the glaciers in the Qilian Mountains have advanced from A.D. 1428 to 1531 , from A.D. 1622 to 1740 , and from A.D. 1797 to 1865 during the Little Ice Age (Xie et al. 1984; Yao et al. 1990; Zhang and Wang 1995). 


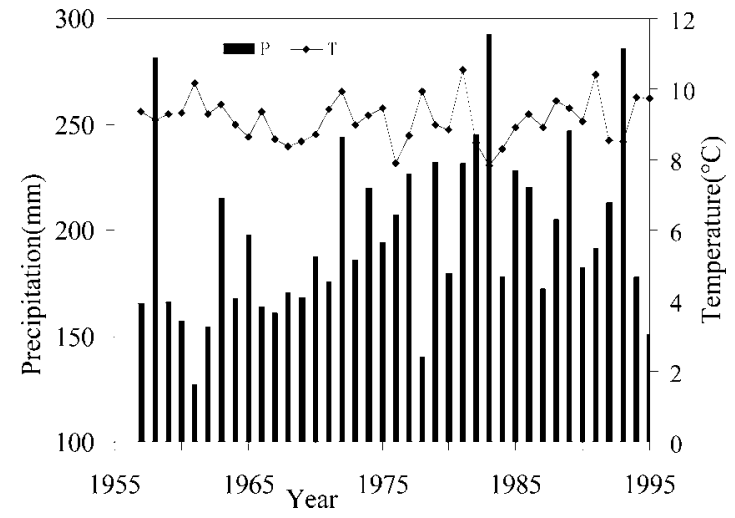

Figure 3. The relationship between mean monthly air temperature and total precipitation from June to August in the western Qilian Mountains, northwestern China.

Records of glacier mass balance and ELA are generally sparse and cover only short periods in the Qilian Mountains. The July First Glacier (glacier inventory code $5 \mathrm{Y} 437 \mathrm{C} 18$ ) is the biggest glacier in the west branch of the Beidahe River system (Wang 1980). Site observations of mass balance and ELA for the July First Glacier were carried out in 1959, from 1974 to 1979 , and from 1983 to 1988 (Wang et al. 1984; Liu et al. 1992). Liu et al. (1992) interpolated the missing ELA values from 1956 to 1988 based on a significant correlation between summer surface temperatures at the July First Glacier meteorological station and the Jiuquan meteorological station (upper air temperature at $650 \mathrm{hPa}$ ).

\section{Study Sites}

The climate in the Qilian Mountains has a typical continental character and presents a distinct vertical zonality. The vegetation also shows zonality. Moving from low to high elevation, the vegetation patterns in the western Qilian Mountains begin with a mountain desert belt $(2,000$ to 2,600 $\mathrm{m}$ a.s.1.), then continue with a mountain steppe belt (2,600 to $3,350 \mathrm{~m}$ a.s.l.), subalpine steppe (3,350 to 3,900 $\mathrm{m}$ a.s.l.), and alpine cold-desert meadow (above 3,900 $\mathrm{m}$ a.s.1.). Because total annual precipitation in the western Qilian Mountains is generally less than $300 \mathrm{~mm}$, there is insufficient moisture to support forest, thus the woody vegetation
Table 1. Characteristics of the sampling sites in the western Qilian Mountains, northwestern China.

\begin{tabular}{|c|c|c|c|c|}
\hline & \multicolumn{4}{|c|}{ Site Code } \\
\hline & $\mathrm{HC} 1$ & $\mathrm{HC} 2$ & $\mathrm{HC} 3$ & $\mathrm{HC} 4$ \\
\hline Latitude $(\mathrm{N})$ & $39^{\circ} 28^{\prime}$ & $39^{\circ} 20^{\prime}$ & $39^{\circ} 16^{\prime}$ & $39^{\circ} 18^{\prime}$ \\
\hline Longitude (E) & $97^{\circ} 39^{\prime}$ & $97^{\circ} 42^{\prime}$ & $97^{\circ} 43^{\prime}$ & $97^{\circ} 42^{\prime}$ \\
\hline $\begin{array}{l}\text { Elevation (m } \\
\text { a.s.l.) }\end{array}$ & 3333 & 3620 & 3820 & 3584 \\
\hline $\begin{array}{l}\text { Average stand } \\
\text { height }(\mathrm{cm})\end{array}$ & 80 & 70 & 50 & 130 \\
\hline $\begin{array}{l}\text { Relative height of } \\
\text { the terrace } \\
\text { above the main } \\
\text { river bed }(\mathrm{cm})\end{array}$ & $50-70$ & $50-120$ & $20-80$ & $70-120$ \\
\hline $\begin{array}{l}\text { River course } \\
\text { River valley } \\
\text { width (m) }\end{array}$ & Northward & Eastward & Westward & Northward \\
\hline
\end{tabular}

is dominated by shrubs such as sea buckthorn, Caragana stenophylla, and Salix matsudana (Wu 1984; Wen and Zhang 2002).

Field investigations were undertaken during the summer of 2004 in the Liuquangou River valley, which is fed by meltwater from the July First Glacier. At our study sites in the river valley, only sea buckthorn is found between 3,000 and 4,000 m elevation, and it usually forms dense, homogeneous stands accompanied by grasses such as Dasiphora fruticosa and Potentilla spp. We sampled four sites ( $\mathrm{HC} 1, \mathrm{HC} 2, \mathrm{HC} 3$, and $\mathrm{HC} 4)$ with different aspects and elevations (Table 1). $\mathrm{HC} 1$ is the lowest-elevation site, and $\mathrm{HC} 3$ is the highest site; both are located about $1.5 \mathrm{~km}$ from the July First Glacier and at a relative elevation of about $400 \mathrm{~m}$ below its terminus.

The shrub stands are generally found on a terrace 20 to $120 \mathrm{~cm}$ above the main river bed. The soil in these stands is bouldery debris, with coarse sand filling the interstices. A very thin layer of shrub litter sits on the soil surface, and soil has a low water-holding capacity (Figure 4). The main roots of sea buckthorn are distributed mostly in the upper $20 \mathrm{~cm}$ of the soil. Sea buckthorn is a dioecious perennial deciduous shrub with a wide ecological spectrum. Sea buckthorn is found from $2^{\circ}$ to $123^{\circ} \mathrm{E}$ and from $27^{\circ}$ to $69^{\circ} \mathrm{N}$ (Hu 2006), and can grow near the polar tree limit, near river beds in 
temperate zones, and on very dry slopes near the Mediterranean coast (Schweingruber 1996); it has even been found above 5,200 m elevation in the Qinghai-Tibetan plateau because of its ability to tolerate low-fertility soil, its drought resistance, and its strong ability to sprout from its roots $\mathrm{Hu}$ 2006). The mean annual temperature where sea buckthorn is found in the Qilian Mountains ranges from -4.2 to $-5.7^{\circ} \mathrm{C}$. Natural pure stands of sea buckthorn generally occupy floodplains, river terraces, and alluvial fans (Hu and Zheng 2005).

\section{Dendrochronological Analysis}

At each site, at least 20 old shrubs were selected and discs were collected from the base of each stem. In the laboratory, the sample discs were airdried, planed, and sanded with progressively finer sandpaper (grit ranges: 100, 240, 500, and 1,000) to enhance the visibility of the boundaries between the annual rings. Some discs required additional planing to ensure that the cross-sections were perpendicular to the stem. Tree rings on each disc were crossdated visually using skeleton plots along two to three radii. False and missing rings were easily identified by comparing the two to three radii used in each cross-section. Ring widths were measured along two radii with a Lintab tree-ring measurement system to the nearest $0.01 \mathrm{~mm}$. A few discs were measured along only one radius because of their extreme eccentricity.

The measured tree-ring sequences were then rechecked using the COFECHA software (Holmes 1983). Segments that were not significantly correlated within discs were remeasured and corrected or otherwise omitted from further analysis in order to prevent undetected missing rings, misinterpreted false rings or operator error affecting the chronologies. Tree-ring chronologies were standardized to remove growth trends that occur as a result of variations in tree physiology or in stand dynamics. All standardized chronologies were developed using the ARSTAN software (Fritts 1976; Cook and Peters 1981; Grissino-Mayer et al. 1996). This procedure involved the fitting of linear or negative-exponential curves to the ring-width series. The dimensionless series were then averaged together using a method based on bi-weighted robust

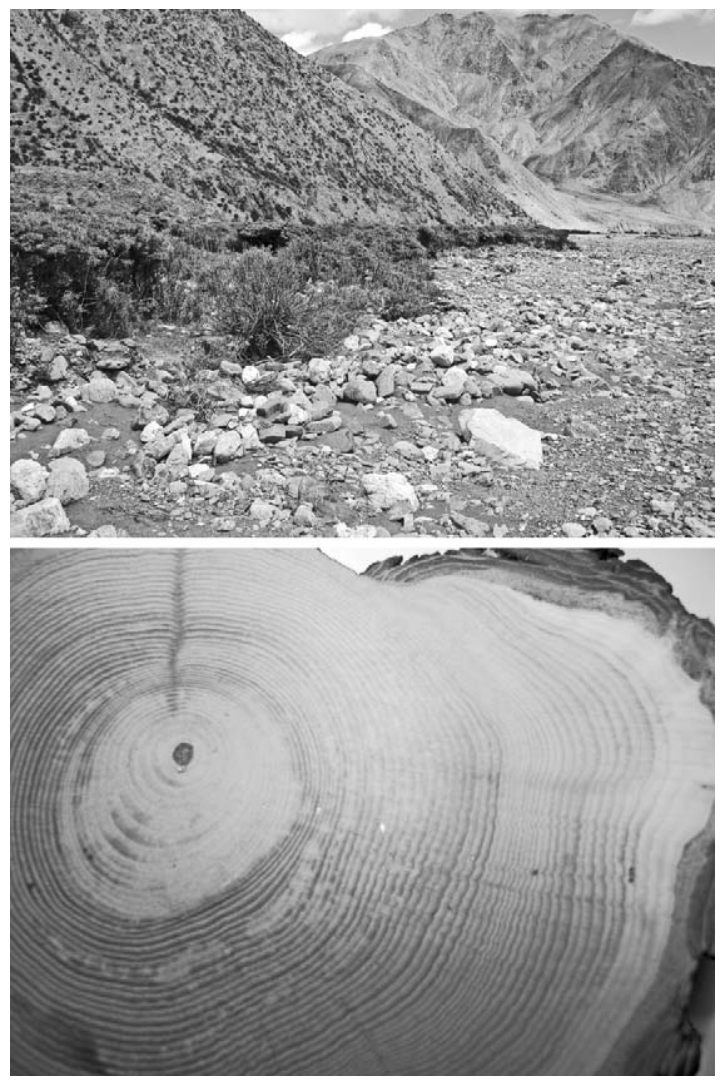

Figure 4. Sea buckthorn stands and a typical tree-ring sequence on the stem cross-section at the HC4 sampling site in the Liuquangou River valley in the western Qilian Mountains. The view is looking north from the terminal moraine of the July First Glacier. Note the bouldery debris that forms the soil and the sensitivity of sea buckthorn's radial growth to environment changes.

means to produce standardized ring-width chronologies for each sampling site. Chronological statistics, such as the mean sensitivity (a measure of the annual variability in tree rings), serial correlation (a measure of the amount of common signal among tree-ring sequences), signal to noise ratio (a measure of the strength of the common signals relative to the uncommon signals that represent noise), and autocorrelation (a measure of the association between growth in the previous year and that in the current year), were obtained to describe the characteristics of the tree-ring chronologies.

Values of the subsample signal strength (SSS) provide a useful statistical tool for determining the 
sample size needed to capture the theoretical population signal of tree-ring variation (Larocque and Smith 2005). We used SSS values above 0.80 to identify a cut-off year in the chronologies, above which there was sufficient sample robustness to reconstruct a reliable time series (Wigley et al. 1984).

We also combined the samples into a regional chronology for use in our dendroclimatological analysis when the site chronologies were significantly correlated.

\section{Dendroclimatological Analysis}

Response-function analysis was used to quantify the relationship between tree-ring chronologies and climate variables using DENDROCLIM2002 software (Biondi and Waikul 2004). The total monthly precipitation and mean monthly temperature over a 13-month period from September of the previous year to September of the current year were used as predictor variables to determine the significance of their effects on concurrent ring growth. Correlation between the sites using the standardized tree-ring indices and the glacier data (mass balance and ELAs in 1959, from 1974 to 1977, and from 1983 to 1988 by Liu et al. (1992)) for the July First Glacier was assessed using SPSS version 11.5 software (SPSS Inc., Chicago, Ill.) because the glacier data were short and discontinuous time series. Significant variables $(p<0.05)$ were selected to verify potential dendroclimatological relationships. The significant variables were then combined with the ring-width indices to reconstruct a time series that predicted past climate series and glacier ELA series. Linear regression was used to establish the relationships between climate and the ring-width index, and the proportion of the variance that was explained by the regression was also calculated to assess the reliability of the conversion equation. The reduction of error $(R E)$ statistic is commonly used to test the accuracy of a regression model (Fritts 1976; Wu 1990), so we calculated that statistic for our model. In addition, we used the interpolated glacier ELA series (Liu et al. 1992) to assess the reconstructions. The cumulative-departure method was introduced to interpret phase changes in the reconstruction curve over large time scales (Gou et al. 2001; Yan et al. 2003).

\section{RESULTS}

\section{Ring-Width Chronologies}

Ring-width chronologies for $H$. rhamnoides were developed for each of the four study sites. The ring-width chronologies extended back to 1931, 1946, 1949, and 1918, respectively, at the $\mathrm{HC} 1, \mathrm{HC} 2, \mathrm{HC} 3$, and HC4 sites. The cut-off years determined based on the SSS (SSS > 0.80) were 1950, 1947, 1952, and 1938, respectively, for the $\mathrm{HC} 1, \mathrm{HC} 2, \mathrm{HC} 3$, and $\mathrm{HC} 4$ sites (Figure 5). Although there were many differences between the four chronologies for the four sites, there were nonetheless similar patterns such as the presence of characteristic narrow rings in the same pointer years, such as 1965, 1974, 1995, and 2001.

The chronological statistics are presented in Table 2 . The mean sensitivity ranged from 0.221 to 0.310 , indicating that high inter-annual variability was present in the ring widths and that the chronology was sensitive to yearly environmental changes. The values of the correlations among all radii $(0.240$ to 0.432$)$ and discs (0.232 to 0.423$)$, and the signal to noise ratios (5.287 to 12.475 ), suggest that the individual shrubs at each site preserved evidence of common environmental signals, but also of other effects such as competition between individuals. The high first-order autocorrelations (0.545 to 0.701) suggest the existence of low-frequency variation in the chronology caused by the propagation of climatic effects from one year to the next.

The relationships among the four chronologies showed significant coincidences between the HC4 chronology and the $\mathrm{HC} 2$ and $\mathrm{HC} 3$ chronologies. The Pearson correlation coefficients were 0.52 ( $\mathrm{n}$ $=56)$ and $0.38(\mathrm{n}=55)$, and the two-tailed tests showed significance at $\mathrm{p}=0.0001$ and 0.004 , respectively (Table 3 ). The $\mathrm{HC} 1$ chronology was not significantly correlated with the $\mathrm{HC} 2, \mathrm{HC} 3$, and HC4 chronologies $(\mathrm{p}=0.42, \mathrm{~N}=56)$. Thus, the regional chronology $\mathrm{HC}$ was developed using all of the samples from the $\mathrm{HC} 2, \mathrm{HC} 3$, and $\mathrm{HC} 4$ sites but excluding samples from HC1 (Figure 5). 

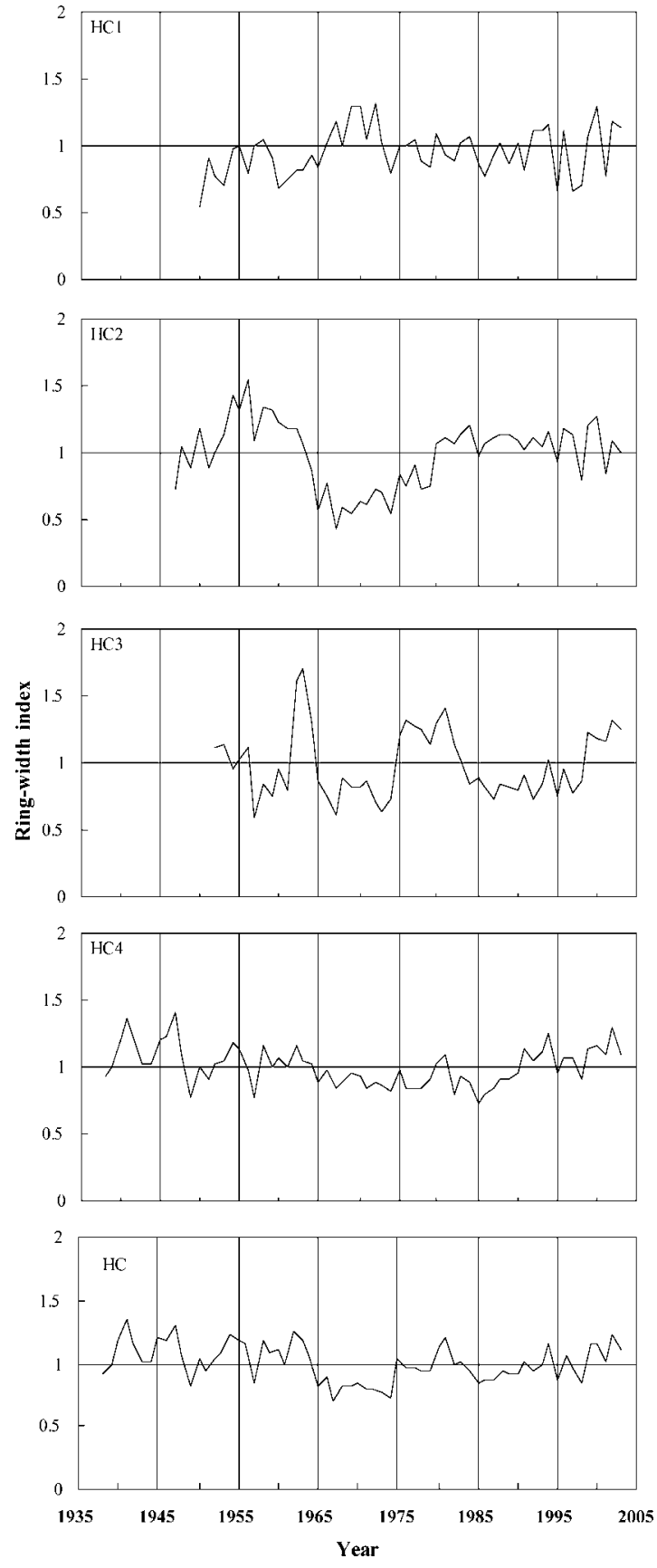

Figure 5. Ring-width chronologies for sea buckthorn (SSS > 0.80 ) at the $\mathrm{HC} 1, \mathrm{HC} 2, \mathrm{HC} 3$, and $\mathrm{HC} 4$ sampling sites near the July First Glacier in the western Qilian Mountains, northwestern China. HC represents the regional chronology established from the $\mathrm{HC} 2, \mathrm{HC} 3$ and $\mathrm{HC} 4$ sampling sites. Data from $\mathrm{HC} 1$ was excluded because it was not significantly correlated with the other sites (Table 3).

\section{Relationships between Climate and Shrub Growth}

\section{Response of Radial Growth to Mean Monthly Temperature and Total Monthly Precipitation}

The results of our response-function analysis showed that only the regional chronology (HC) presented a significantly positive correlation with air temperature in July of the current year (Figure 6 ); none of the four chronologies showed a significant correlation with the mean monthly temperature and total monthly precipitation (data not shown). Because the regional chronology was so short, there was no value in reconstructing the mean monthly temperature.

\section{Radial Growth and Glacier ELA}

We also compared the glacier's ELA with shrub radial growth. Correlations between the five chronologies and ELA for the July First Glacier were analyzed for 1959, from 1974 to 1977, and from 1983 to 1988 . The results showed that the HC1 chronology was significantly negatively correlated with ELA $(\mathrm{r}=-0.744, \mathrm{p}=0.022, \mathrm{n}=9)$. The correlation coefficients of the other chronologies were not significant $(p>0.05)$. The ELA for the period from 1950 to 2003 was reconstructed using linear regression based on the $\mathrm{HC} 1$ chronology (Figure 7). Analysis of the model statistics and evaluation of the residuals indicated that $\mathrm{HC} 1$ had significant predictive power: it explained $55.3 \%$ of the variance. The $R E$ statistic between the reconstructed and observed data was as high as 0.999, indicating that the ELA reconstruction for the July First Glacier was reliable.

To understand phase changes in the ELA on a decadal time scale, the reconstruction curve was analyzed using a cumulative-departure method (Figure 8). The cumulative-departure statistic is interpreted as follows: a positive cumulative departure means that the ELA value increases, and that the glacier is thus receding farther up the mountain, whereas a negative departure means that the ELA value decreases and the glacier is advancing down the mountain. The curve for the ELA of the July First Glacier showed a rising trend from the 
Table 2. Characteristics of the four growth-ring chronologies in the western Qilian Mountains, northwestern China.

\begin{tabular}{lcccc}
\hline & \multicolumn{3}{c}{ Site Code } \\
\cline { 2 - 5 } & HC1 & HC2 & HC3 & HC4 \\
\hline Chronology length (years) & $72(1931-2003)$ & $57(1946-2003)$ & $54(1949-2003)$ & $84(1918-2003)$ \\
Discs/radii & $23 / 42$ & $18 / 36$ & $26 / 50$ & 0.287 \\
Mean sensitivity & 0.310 & 0.255 & 0.343 & 0.221 \\
Correlation among all radii & 0.249 & 0.432 & 0.331 & 0.240 \\
Correlation between discs & 0.237 & 0.423 & 0.762 & 0.232 \\
Correlation within discs & 0.633 & 0.698 & 8.898 & 0.654 \\
Signal to noise ratio & 5.287 & 12.475 & 0.579 & 8.465 \\
First-order autocorrelation & 0.545 & 0.643 & & 0.701 \\
\hline
\end{tabular}

1950s to the mid-1960s, whereas a declining trend was evident from the mid-1960s to the mid-1970s. After the mid-1970s, the ELA remained relatively stable. In the most recent decade, the interannual range in the curve was very large compared with the values from the 1970s and 1980s.

\section{DISCUSSION AND CONCLUSION}

The results of the response-function analysis reflected the strength of the linear relationship between climatic data and ring width (Fritts 1976). The radial growth of the shrubs responded differently to environmental change at different sampling sites. The four shrub stands grow on sites with different aspects and elevations, suggesting that characteristics of the microclimate (such as sunlight duration, length of the growing season, and precipitation) varied among the stands. The

Table 3. Correlation coefficients matrix for the four site chronologies.

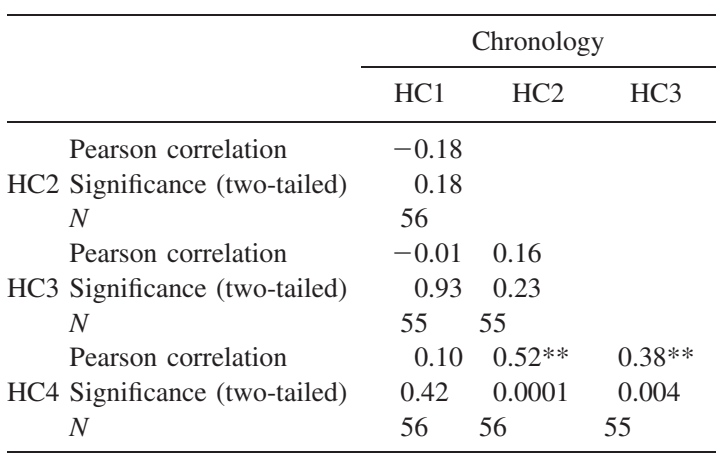

** Correlation is significant at $\mathrm{p}<0.01$ (two-tailed test).
HC regional chronology was successfully extracted from common information in the sequences at three of the sampling sites, and an enhanced common signal was revealed by the response-function analysis.

Figure 2 shows that the growing season, which corresponds to the period during which the temperature is higher than $5^{\circ} \mathrm{C}$, occurred mainly in June, July, and August in the western Qilian Mountains. The high temperature in June would activate growth of the shrubs and extend the growing season. Simultaneously, soil moisture would be supplied through melting of the snow cover and of the frozen earth. July and August are hotter months, and are also the rainy season, so the tem-

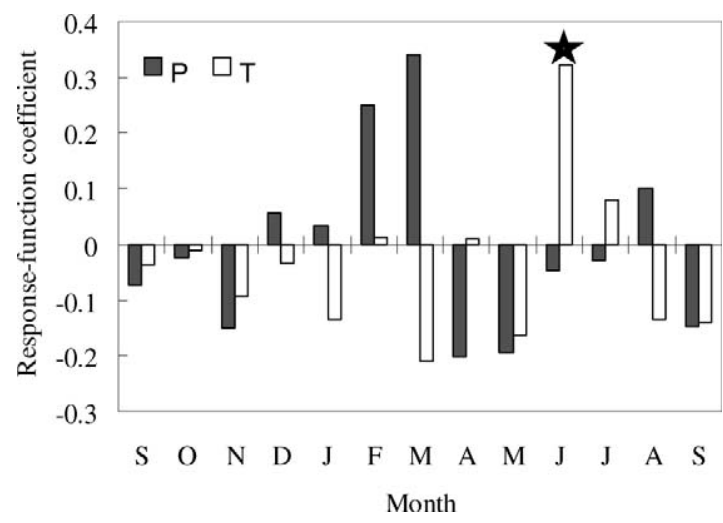

Figure 6. Response-function coefficients for the relationships between radial growth of sea buckthorn and the monthly mean air temperature and total monthly precipitation for the regional climatic data set (from September in the previous year to September in current year) from 1959 to 1996. Open bars are temperature, filled bars are precipitation, and asterisk is significance at the 0.05 level as tested by bootstrap method. 


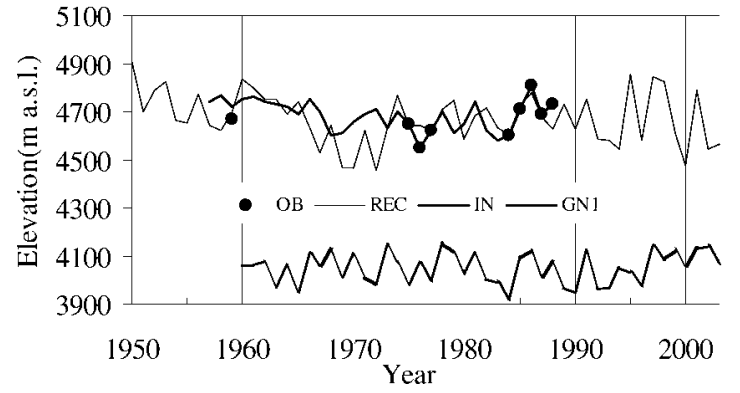

Figure 7. ELA curves for the July First Glacier in the western Qilian Mountains and for Glacier No. 1 in the Tianshan Mountains. OB, observed series (1959, 1975-1977, and 1983-1988; Wang et al. 1984; Liu et al. 1992); REC, reconstructed series (from 1950 to 2003); IN, interpolated series (from 1957 to 1988; Liu et al. 1992); GN1, Glacier No. 1 in the drainage area of the Urumqi River in the Tianshan Mountains (from 1960 to 2003; Yang et al. 2005).

perature and soil moisture were sufficient for shrub growth. Thus, the response analysis showed a significant positive relationship between ring width and the mean monthly temperature in June of the current year. This result was similar to those of previous studies, in which the temperature of the growing season played an important role in treering growth near the cold high-elevation treeline (Jacoby et al. 1985; Zhang and Hebda 2004). However, our results differed from previous studies that showed annual radial increment being further controlled by precipitation and temperature prior to the growing season near the treeline in the central Tianshan Mountains (Wang et al. 2005), and that showed spring precipitation as a significant factor for tree growth at high-elevation sites in the central Qilian Mountains (Gou et al. 2005).

Glacier ELA is sensitive to changes in both air temperature and precipitation, and was therefore expected to be closely correlated with the ringwidth chronology. Rigorous verification of the reconstructions in our study is problematic owing to the limited duration of the ELA time series (i.e. only 9 years). Although correlation analysis suggested a significant relationship for one site, the lack of sufficient historical data prevented us from partitioning the time series in half for model calibration and verification of the predicted values. To overcome the limited availability of instrumental data, we compared our reconstructions with the interpolated series based upon the upper air tem-

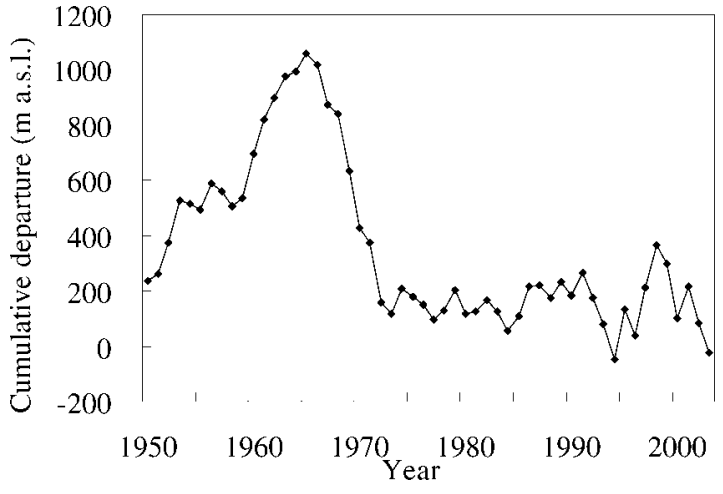

Figure 8. The cumulative-departure curve for the reconstructed glacier ELA of the July First Glacier, western Qilian Mountains.

perature model developed by Liu et al. (1992) for the July First Glacier. The results showed a significant correlation for these two time-series $(\mathrm{r}=$ $0.37, \mathrm{p}=0.038, \mathrm{n}=32$; Figure 7), and that they presented similar changes on a decadal scale.

Change in glacier ELA is significantly negatively correlated with fluctuations in glacier mass balance (Liu et al. 1992), such that years with rising reconstructed series of ELA corresponded to negative values of mass balance, whereas declining years corresponded to positive values of mass balance.

A shift in glacier mass balance and ELA in 1968 was documented by Liu et al. (1992) based on an interpolated series. A shift in 1967 was also reported by Kang and Ding (1981) based on their analyses of upper atmospheric conditions at 500 $\mathrm{hPa}$ above the Qilian Mountains. Our study showed that change to occur in 1965. Subsequently, the glacier mass balance and ELA entered a stable period after 1973 (Figure 8). This shift in glacier mass balance from negative to positive on a decadal scale is similar to the results for other representative glaciers in China, such as Glacier No. 1 in the drainage area of the Urumqi River in the Tianshan Mountains (Yang et al. 2005; Figure 7), and was also synchronous with data for other glaciers worldwide (Liu et al. 1992). The changes in glacier mass balance and ELA have responded sensitively to global climate changes (Kang and Ding 1981; Liu et al. 1992; Pu et al. 2005). The observed results at the Tuole meteorological sta- 
tion near the July First Glacier since 1974 showed that the 1970s had more rainfall and lower temperatures than in previous periods, which likely contributed to glacier accumulation. In the 1980s, however, temperatures were higher than in the 1970 s, and precipitation was similar to that in the 1970s. This suggests that the glacier mass balance was in a stable state. During the past few decades, the climate shifted from a warm-dry pattern to warm-humid (Shi et al. 2002). This trend resulted in increased glacial ablation, and during this period, the reconstructed ELAs fluctuated widely.

The glacier had a negative mass balance during winter in some years, with values even more negative than those during summer such as 1975/ 1976, 1976/1977, and 1984/1985 (Liu et al. 1992), although the ablation and accumulation of the July First Glacier occurred mainly during the warm season. The behavior of the glacier during the cold season could not be recorded in the growth rings because shrub radial growth ceases during this period.

The regional chronology showed that shrub radial growth in the river valley at three high-elevation sites ( $\mathrm{HC} 2, \mathrm{HC} 3$, and $\mathrm{HC} 4)$ showed a significant positive correlation with the mean monthly temperature early in the growing season (June) of the current year, and this phenomenon has a clear biological meaning. We also attempted to reconstruct the ELA of the July First Glacier using the low-elevation site chronology $\mathrm{HC} 1$, and the reconstructed ELA series showed a similar trend to that in other records on a decadal scale from 1950 to 2003. Reconstruction of a robust proxy record of glacier change from shrub growth-ring data thus appears to be a promising alternative where trees are unavailable for sampling, but will require further work and a longer series of instrument records in future studies.

\section{ACKNOWLEDGMENTS}

This work was supported by the National Natural Science Foundation of China (Grant No. 40371009) and the projects which initiated by China Science and Technology Ministry (Grant No. 2005BA517A03; 2006BAD26B02). We thank Dr. Qibing Zhang in Institute of Botany, Chinese
Academy of Sciences for suggestions on an early version of the paper. We thank editors Dr. Henri D. Grissino-Mayer and Dr. Steven W. Leavitt for improving the English of the text, and two anonymous reviewers for their helpful comments on this study.

\section{REFERENCES CITED}

Begin, Y., and L. Filion, 1995. A recent downward expansion of shoreline shrubs at Lake Bienville (subarctic Quebec). Geomorphology 13:271-282.

Benn, D. I., and F. Lehmkuhl, 2000. Mass balance and equilibrium-line altitudes of glaciers in high-mountain environments. Quaternary International 65/66:15-29.

Biondi, F., and K. Waikul, 2004. DENDROCLIM2002: a C ++ program for statistical calibration of climate signals in treering chronologies. Computers \& Geosciences 30:303-311.

Chen, Z., 1996. Carbon and Oxygen Isotopic Compositions of Tree Rings from a Recent T. aphylla Specimen, Death Valley, California. M.S. thesis, University of Alberta, Calgary.

Cook, E. R., and K. Peters, 1981. The smoothing spline: a new approach to standardizing forest interior tree-ring width series for dendroclimatic studies. Tree Ring Bulletin 41:45-53.

Friedman, J. M., W. R. Osterkamp, and W. M. Lewis, 1996. The role of vegetation and bed-level fluctuations in the process of channel narrowing. Geomorphology 14:341-351.

Fritts, H. C., 1976. Tree Rings and Climate. Academic Press, London; $567 \mathrm{pp}$.

Gao, Q. Z., and X. Y. Yang, 1984. The features of interior rivers and feeding of glacial meltwater in the Hexi Region, Gansu Province. Lanzhou Institute of Glaciology and Geocryology, Chinese Academy of Sciences. Memoirs of Lanzhou Institute of Glaciology and Geocryology, Chinese Academy of Sciences. No. 5, Glacier Variations and Utilizations in Qilian Mountain, Science Press, Beijing; pp. 131141.

Gou, X., F. Chen, M. Yang, J. Li, J. Peng, and L. Jin, 2005. Climatic response of thick leaf spruce (Picea crassifolia) tree-ring width at different elevations over Qilian Mountains, Northwestern China. Journal of Arid Environments 61:513524.

Gou, X. H., F. H. Chen, Y. J. Wang, and X. M. Shao, 2001. Spring precipitation reconstructed in the east of the Qilian Mountains during the last 280a by tree-ring width. Journal of Glaciology and Geocryology 23(3):292-296.

Grissino-Mayer, H. D., 1993. An updated list of species used in tree-ring research. Tree-Ring Bulletin 53:17-45.

Grissino-Mayer, H. D., R. L. Holmes, and H. C. Fritts, Editors, 1996. The International Tree-Ring Data Bank Program Library, User's Manual, Version 2. International Tree-Ring Data Bank, Tucson, Arizona.

Holmes, R. L., 1983. Computer-assisted quality control in treering dating and measurement. Tree-Ring Bulletin 43:69-78.

Hu, J. Z., 2006. Strategic thoughts on regionalization of plantation and development of Hippophae in three north areas 
of China. Research on Soil and Water Conservation 13(1): 4-7.

Hu, J. Z., and J. L. Zheng, 2005. Characteristics of distribution and composition of Hippophae rhamnoides ssp. sinensis in southern parts of Qilian Mountains. International Hippophae Research and Exploitation 3(2):38-42.

Jacoby, G. C., E. R. Cook, and I. D. Ulan, 1985. Reconstructed summer degree days in central Alaska and Northwestern Canada since 1524. Quaternary Research 23:18-26.

Kang, X. C., and L. F. Ding, 1981. The correlation between the glacial mass balance, snowline location and weather climate conditions in Tianshan Mountain and Qilian Mountain. Journal of Glaciology and Geocryology 3(3):53-58.

Larocque, S. J., and D. J. Smith, 2005. 'Little Ice Age' proxy glacier mass balance records reconstructed from tree rings in the Mt Waddington area, British Columbia coast mountains, Canada. The Holocene 15:748-757.

Lipp, J., P. Trimborn, T. Edwards, Y. Waisel, and D. Yakir, 1996. Climatic effects on the $\delta^{18} \mathrm{O}$ and $\delta^{13} \mathrm{C}$ of cellulose in the desert tree Tamarix jordanis. Geochimica et Cosmochimica Acta 60:3305-3309.

Liu, C. H., Z. C. Xie, H. A. Yang, and Y. Z. Wei, 1992. Observation, interpolation and trend study of glacier mass balance on the July First Glacier in Qilian Mountains. Memoirs of Lanzhou Institute of Glaciology and Geocryology, Chinese Academy of Sciences. No. 7, The Monitoring of Glacier, Climate, Runoff Changes and the Research of Cold Region Hydrology in Qilian Mountain, Science Press, Beijing; pp. 21-33.

Liu, S. Y., Y. P. Shen, W. X. Sun, and G. Li, 2002. Glacier variation since maximum of the Little Ice Age in the western Qilian Mountain, northwest China. Journal of Glaciology and Geocryology 24:227-233.

Paterson, W. S. B., 1994. The Physics of Glaciers, 3rd ed. Pergamon, Oxford; $480 \mathrm{pp}$.

$\mathrm{Pu}$, J. C., T. D. Yao, K. Q. Duan, A. Sakai, K. Fujita, and Y. Matsuda, 2005. Mass balance of the July First Glacier in the Qilian Mountains: a new observation. Journal of Glaciology and Geocryology 27:199-206.

Schweingruber, F. H., 1996. Tree Rings and Environment, Dendroeology. Paul Haupt Verlag, Berne, Switzerland; 609 pp.

Shi, Y. F., 2000. Glaciers and their Environments in China: The Present, Past and Future. Science Press, Beijing; 410 pp.

Shi, Y. F., Y. P. Shen, and R. J. Hu, 2002. Preliminary study on signal, impact and foreground of climatic shift from warm-dry to warm-humid in Northwest China. Journal of Glaciology and Geocryology 24:219-226.

Stromberg, J., 1998. Dynamics of Fremont cottonwood (Populus fremontii) and saltcedar (Tamarix chinensis) populations along the San Pedro River, Arizona. Journal of Arid Environments 40:133-155.

Wang, T., H. Ren, and K. Ma, 2005. Climatic signals in tree rings of Picea schrenkiana along an altitudinal gradient in the central Tianshan Mountains, Northwestern China. Trees 19:735-741.

Wang, Z. T., 1980. Glacier Inventory of China: Qilian Mountains. Lanzhou Institute of Glaciology and Cryopedology,
Chinese Academy of Sciences. Science Press, Beijing; 249 pp.

Wang, Z. X., Z. C. Xie, and G. H. Wu, 1984. Mass balance of glacier in Qilian Mountain. Lanzhou Institute of Glaciology and Geocryology, Chinese Academy of Sciences. Memoirs of Lanzhou Institute of Glaciology and Geocryology, Chinese Academy of Sciences, No. 5, Glacier Variations and Utilizations in Qilian Mountains. Science Press, Beijing; pp. 41-53.

Watson, E., and B. H. Luckman, 2004. Tree-ring-based massbalance estimates for the past 300 years at Peyto Glacier, Alberta, Canada. Quaternary Research 62:9-18.

Wen, Y. L., and H. Zhang, 2002. Species diversity of plant communities along an altitudinal gradient in Qilian Mountains (northern slope). Journal of Gansu Forestry Science and Technology 27:37-43.

Wigley, T. M. L., K. R. Briffa, and P. D. Jones, 1984. On the average value of correlated time series, with applications in dendroclimatology and hydrometeorology. Journal of Climate and Applied Meteorology 23:201-213.

Wu, G. H., 1984. Features of physical geography and glacier resources in Qilian Mountains. Lanzhou Institute of Glaciology and Geocryology, Chinese Academy of Sciences. Memoirs of Lanzhou Institute of Glaciology and Geocryology, Chinese Academy of Sciences, No. 5, Glacier Variations and Utilizations in Qilian Mountains. Science Press, Beijing; pp. 1-8.

Wu, X. D., 1990. Tree Rings and Climate Change. Meteorology Publisher, Beijing; 369 pp.

Xiao, S. C., H. L. Xiao, J. H. Si, X. B. Ji, and F. M. Liu, 2005. Lake level changes recorded by tree rings of lakeshore shrubs: a case study at the Lake West-Juyan, Inner Mongolia, China. Journal of Integrative Plant Biology 47:13031314.

Xiao, S. C., H. L. Xiao, Y. X. Song, Z. H. Duan, and M. F. Lu, 2006. Dendrochronology study on response of Reaumuria soongorica to climate variation in an arid desert region. Journal of Desert Research 26:548-552.

Xie, Z. C., G. H. Wu, and L. L. Wang, 1984. Recent advance and retreat of glaciers in Qilian Mountains. Lanzhou Institute of Glaciology and Geocryology, Chinese Academy of Sciences. Memoirs of Lanzhou Institute of Glaciology and Geocryology, Chinese Academy of Sciences, No. 5, Glacier Variations and Utilizations in Qilian Mountains. Science Press, Beijing; pp. 82-90.

Yan, M. H., W. Deng, and P. Q. Chen, 2003. Analysis of climate jumps in the Sanjiang plain. Scientia Geographica Sinica 23:661-667.

Yang, H., Z. Li, B. Ye, K. Jiao, Z. Jing, and Z. Zhao, 2005. Study on mass balance and process of Glacier No. 1 at the headwater of the Urumqi River in the past 44 years. Arid Land Geography 28:76-80.

Yang, W. B., R. J. Spencer, and H. R. Krouse, 1996. Stable sulfur isotope hydrogeochemical studies using desert shrubs and tree rings, Death Valley, California, USA. Geochimica et Cosmochimica Acta 60:3015-3022.

Yao, T. D., Z. C. Xie, and X. L. Wu, 1990. Climatic records 
since the Little Ice Age from the Dunde Ice Cap. Science in China (Series B) 11:1196-1201.

Zhang, Q. B., and R. J. Hebda, 2004. Variation in radial growth patterns of Pseudotsuga menziesii on the central coast of British Columbia, Canada. Canadian Journal of Forest Research 34:1946-1954.

Zhang, X. S., and Z. T. Wang, 1995. Glacier fluctuations and their future trend in the northwest China. In Impacts of Climate Change on the Water Resources in the Western and Northern China, edited by Y. F. Shi, Shandong Science and Technology Press, Jinan; pp. 53-78.

Received 1 September 2006; accepted 28 March 2007. 